\title{
Artrite de Poncet: relato de caso
}

\author{
Louise Cardoso Schweitzer ${ }^{1}$, Francine Lipnharski ${ }^{1}$, Sergio Henrique Prezzi ${ }^{3}$
}

\begin{abstract}
RESUMO
A doença de Poncet é uma condição clínica rara, caracterizada por um acometimento poliarticular em um paciente com diagnóstico de tuberculose, sem evidência de invasão direta do bacilo nas articulações, configurando uma artrite reativa. Documentamos um caso em Porto Alegre: um homem de 56 anos, com evidência de poliartrite aditiva de grandes articulações, investigada há 5 anos, sem diagnóstico definido. Ele havia sido submetido a uma nefrectomia unilateral há 5 anos, e o exame anatomopatológico do órgão revelou tuberculose renal. O teste tuberculínico atual revelou um forte reator $(\mathrm{PPD}=20 \mathrm{~mm})$. Análise do líquido sinovial não demonstrou invasão direta do bacilo. Foi instituído tratamento empírico com tuberculostáticos com remissão clínica após 2 meses. Embasados nesses dados, foi feito diagnóstico de doença de Poncet.
\end{abstract}

Palavras-chave: artrite reativa; tuberculose; relatos de casos.

[Rev Bras Reumatol 2011;51(4):388-93] CElsevier Editora Ltda

\section{INTRODUÇÃO}

Reumatismo tuberculoso, também chamado de doença de Poncet, é uma síndrome rara descrita em 1897 pelo francês A. Poncet. ${ }^{1}$ É caracterizada pelo acometimento articular em pacientes com diagnóstico de tuberculose, não relacionado à invasão direta do micro-organismo, mas sim a uma reação imunológica à tuberculoproteína, configurando uma artrite reativa. Poucos médicos conhecem a doença e a literatura relacionada a essa síndrome é escassa e restrita a relatos de caso, o que torna essa entidade muitas vezes subdiagnosticada. Esse relato tem como objetivo apresentar à sociedade médica um caso de Poncet ocorrido em nosso hospital, bem como revisar aspectos diagnósticos e terapêuticos envolvidos.

\section{RELATO DE CASO}

Um paciente do sexo masculino, 56 anos, branco, natural e procedente de Porto Alegre, pescador e músico, hipertenso, diabético e com história de nefrectomia unilateral há 5 anos, por motivo desconhecido pelo paciente. Dentre os exames realizados na época, a ecografia abdominal mostrava hidronefrose de rim direito e a cintilografia com DMSA revelava ausência de imagem cintilográfica do rim direito e rim esquerdo com hipertrofia compensatória com função levemente deficiente (rim direito $0,8 \%$ e rim esquerdo $25,8 \%$ ). À reabertura do prontuário, foi encontrado o resultado anatomopatológico da peça, que revelava pielonefrite supurativa crônica acentuada com atrofia do parênquima e presença de granulomas tuberculoides com necrose caseosa. Apesar desse dado, não foi realizado tratamento tuberculostático naquele momento. Foi admitido em nosso hospital com história de dor e edema articular há 5 meses, febre vespertina, sudorese noturna e emagrecimento de 20 quilos em 5 anos. Apresentava internações prévias pelo mesmo quadro articular, sem resposta à terapia com colchicina. $\mathrm{O}$ exame físico revelava artrite de joelho e tornozelo direitos e de punho esquerdo. Testes laboratoriais revelaram leucócitos de 11.400 com $63 \%$ de segmentados e proteína $\mathrm{C}$ reativa (PCR) de $154 \mathrm{mg} / \mathrm{dL}$. Exame qualitativo de urina normal. Ácido úrico sérico de 8,8. Raios $\mathrm{X}$ de tórax, de articulações de mãos, punhos, tornozelos, coluna lombossacra, bacia e sacroilíacas não mostraram alterações. Anticorpo antinuclear e fator reumatoide

Recebido em 16/03/2010. Aprovado, após revisão, em 30/04/2011. Os autores declaram a inexistência de conflitos de interesse.

Hospital Nossa Senhora da Conceição, Porto Alegre, RS, Brasil.

1. Médica-residente do Hospital Nossa Senhora da Conceição - Porto Alegre, RS; Universidade Federal de Santa Catarina - UFSC

2. Médico-internista/Intensivista e Preceptor de Medicina Interna do Hospital de Clínicas de Porto Alegre e do Hospital Nossa Senhora da Conceição - Porto Alegre, RS

Correspondência para: Louise Cardoso Schweitzer. Avenida FranciscoTrein, 596 Cristo Redentor, Porto Alegre, RS, Brasil. CEP: $91350-200$. E-mail: louisecs84@gmail.com. 
eram negativos. Foram descartadas doenças sexualmente transmissíveis, inclusive com sorologia anti-HIV negativa. Análise do fluido sinovial do joelho evidenciou líquido turvo com 21.300 células, $70 \%$ de neutrófilos, $8 \%$ de linfócitos, $20 \%$ de monócitos, 30 leucócitos por campo e ausência de cristais birrefringentes. Não foi possível a cultura do líquido sinovial devido à escassez de material. Foi realizada intradermorreação para tuberculose com resultado de $20 \mathrm{~mm}$, considerado teste fortemente positivo. Feito diagnóstico presuntivo de tuberculose ativa, sem foco esclarecido. Devido à baixa probabilidade pré-teste de tuberculose articular, foi feito o diagnóstico clínico de doença de Poncet. Iniciado tratamento com esquema rifampicina-isoniazida-pirazinamida, porém optado pela troca da pirazinamida por etambutol por aumento significativo nos níveis séricos de ácido úrico. Como tratamento inicial da dor, optou-se por prednisona na dose de $30 \mathrm{mg}$ por 3 semanas, com redução gradual da dose por mais 3 semanas até a suspensão. Após 2 meses de tratamento, paciente apresentou melhora completa da dor. Em 15 meses de acompanhamento, paciente apresentou ganho de $10 \mathrm{~kg}$ de peso e permanecia assintomático.

\section{DISCUSSÃO}

Tuberculose é uma doença muito prevalente nos países em desenvolvimento. Sabe-se que aproximadamente $10 \%$ a $11 \%$ dos casos de tuberculose extrapulmonar envolve ossos e articulações, o que corresponde a $1 \%$ a $3 \%$ de todos os casos de tuberculose.

A associação de tuberculose e doenças reumatológicas tem sido bem reconhecida. Franco-Paredes et al. estabeleceram quatro diferentes categorias: (1) envolvimento musculoesquelético direto pelo Mycobacterium tuberculosis, incluindo espondilite, osteomielite, artrite séptica e tenosinovite; (2) M. tuberculosis como um patógeno infeccioso em doença reumatológica, particularmente com o uso de novos agentes terapêuticos; (3) síndromes reumatológicas induzidas por drogas antituberculosas, incluindo tendinopatias, lúpus induzido por fármacos e outros e (4) fenômenos imunológicos reativos, como artrite reativa, eritema nodoso e outros.

A forma de monoartite séptica tuberculosa é amplamente conhecida, na qual a micobactéria pode ser isolada em cultura da articulação acometida. ${ }^{3}$ Entretanto, conforme descrito por Franco-Paredes et al., tuberculose ativa também pode ser complicada por uma artrite reativa estéril, o chamado reumatismo de Poncet. Relembrar e relatar esse assunto é sempre oportuno, sobretudo agora quando ocorre um ressurgimento da tuberculose em nosso meio e globalmente. A tuberculose, mesmo subclínica, deve entrar no rol de possíveis patógenos com potencial de desencadear quadros reativos. Essa possibilidade é mais relevante na medida em que o uso inadvertido de corticosteroides, imunossupressores ou biológicos poderia desencadear reativação ou disseminação da doença.

O mecanismo etiopatogênico dessa enfermidade ainda é assunto bastante controverso na literatura. Dentre as hipóteses mais aceitas, incluem-se o mimetismo molecular e as proteínas de choque térmico. ${ }^{4}$

No mimetismo molecular, há interação entre antígenos do agente infeccioso e componentes do tecido articular. Os argumentos que corroboram essa teoria ${ }^{5}$ são: 1) Modelo da artrite adjuvante de Pearson (1963), na qual uma simples inoculação intradérmica de adjuvante de Freund - um macerado de micobactérias (M. tuberculosis ou Mycobacterium bovis) mortas pelo calor, emulsificado em óleo mineral - induz ao surgimento de artrite murina, 11 a 13 dias após a inoculação. 2) Desenvolvimento de granulomas ósseos e lesões articulares após instilação intravesical de BCG, como terapia alternativa de câncer de bexiga. Pode haver também, nesses casos, surgimento de artrite oligoarticular ou poliarticular, em 3\% dos indivíduos tratados, 1 a 3 meses depois do início da terapia.

Já as proteínas de choque térmico representam um grupo de proteínas produzidas por todas as espécies, quando diante de variados estímulos, como calor, irradiação, infecção viral, citoquinas. Vários patógenos, inclusive a micobactéria, possuem antígenos homólogos a proteínas, sugerindo o papel da autoimunidade. Os antígenos bacilares dividem sequências de aminoácidos com proteoglicanos das cartilagens, produzindo uma reatividade cruzada, mediada por linfócitos T e lesão nas células do hospedeiro. Há algum tipo de predisposição genética, uma vez que genótipos HLA-DR3 e HLA-DR4 mostram resposta exacerbada, mediada pelos linfócitos $\mathrm{T}$, aos antígenos da micobactéria, podendo representar expressão de uma resposta imunogênica comum à tuberculina. ${ }^{5,6}$

$\mathrm{Na}$ doença de Poncet existe comprometimento oligo ou poliarticular mais frequentemente do que monoarticular, assemelhando-se a outras artrites reativas, principalmente envolvendo grandes articulações como joelho, tornozelo e quadril, com frequência acompanhada de derrame articular. Não há evidência microbiológica de invasão da micobactéria na articulação afetada, ${ }^{7}$ os testes sorológicos para autoimunidade são negativos e o teste tuberculínico, bem como as proteínas de fase aguda estão alterados. ${ }^{8}$

Existem alguns critérios diagnósticos propostos por Gilberto Santos Novaes, ${ }^{9}$ após análise de uma série de 25 casos de doença de Poncet, que consistem nos seguintes elementos: a) evidência de tuberculose ativa extra-articular; b) manifestações reumáticas em mais de uma articulação; 
c) ausência de antecedentes pessoais e familiares; d) ausência de comprometimento axial, de coluna vertebral e sacroilíaca; e) resultados inespecíficos dos exames laboratoriais; f) remissão completa das manifestações reumáticas com a quimioterapia antituberculosa, sem sequelas articulares permanentes; g) exclusão de outras doenças reumáticas.

Vale destacar que, com modernos métodos diagnósticos para a tuberculose, talvez se reconheça que a artrite reativa de Poncet é mais prevalente do que se supõe. Dois métodos diagnósticos destacam-se atualmente: o PCR em amostras não colonizáveis, como o líquido sinovial; e ensaios de liberação de interferon gama. Valleala et al. ${ }^{10}$ descreveram um caso de tuberculose diagnosticado por esse método, com confirmação pela resposta terapêutica.

Em nosso paciente foram realizadas radiografias de tórax e das articulações acometidas, que não demonstraram alterações características de tuberculose. Na tuberculose articular, a radiografia normalmente mostra alargamento do espaço articular, derrame articular e pannus. Em pouco tempo, ocorre destruição da cartilagem e erosão do osso subcondral.

O nosso paciente apresentava história de gota e ácido úrico discretamente elevado, o que inicialmente confundiu e atrasou o diagnóstico. Entretanto, na artrite gotosa geralmente há acometimento monoarticular, sendo o primeiro pododáctilo o local mais frequentemente afetado. A tendência é que ocorra em crises e que haja remissão com o tratamento específico com colchicina e anti-inflamatórios, o que não aconteceu nesse paciente. Além disso, o paciente apresentou tuberculose renal 5 anos antes, sem receber tratamento naquele momento. $\mathrm{O}$ teste tuberculínico atual era de $20 \mathrm{~mm}$, considerado um valor fortemente positivo. Infelizmente, nosso serviço não dispõe de métodos diagnósticos modernos de pesquisa da micobactéria, tampouco foi possível realizar cultura do líquido sinovial devido à escassez de material. Entretanto, com os dados disponíveis, foi considerada como principal hipótese a artrite de Poncet. É importante a identificação precoce dessa condição para que o tratamento específico seja instituído já que a artrite resolve-se completamente com a terapia tuberculostática em poucas semanas.

\section{REFERENCES}

\section{REFERÊNCIAS}

1. Poncet A. Apud in Bloxham CA, Addy DP. Poncet's disease: parainfective tuberculous polyarthropathy. BMJ 1978; 1(6127):1590.

2. Ideguchi H, Ohno S, Takase K, Tsukahara T, Kaneko T, Ishigatsubo Y. A case of Poncet's disease (tuberculous rheumatism). Rheumatol Int 2009; 29:1097-9.

3. Kroot EJA, Hazes JMW, Colin EM, Dolhain RJEM. Poncet's disease - reactive arthritis accompanying tuberculosis. Two case reports and a review of the literature. Rheumatology 2007; 46:484-9.

4. Pereira JCB. Artropatia de Poncet - série de casos. Pulmão RJ 2005; 14(4):321-4.

5. Tischler M, Schonfeld Y. Tuberculose et autoimmunité: òu en sommes-nous? Ann Inst Pasteur 1996; 7(2):133-6.

6. Southwood TR, Gaston JSH. The molecular basis for Poncet's disease. Rev Bras Reumatol 1990; 29(6):491.

7. Ozgul A, Baylan O, Taskaynatan MA, Kalyon TA. Poncet's disease (tuberculous rheumatism): two case reports and review of the literature. Int J Tuberc Lung Dis 2005; 9(7):822-4.

8. Malaviya AN, Kotwal PP. Arthritis associated with tuberculosis. Best Pract Res Clin Rheumatol 2003; 17(2):319-43.

9. Novaes GS, Kalil G, Borrelli FE. Critérios de diagnóstico da doença de Poncet. Rev Bras Reumatol 1992; 32(1):20-6.

10. Valleala H, Tuuminen T, Repo H, Eklund KK, Leirisalo-Repo M. Nat Rev Rheumatol 2009; 5(11):643-7. 